\title{
Mass Spectra Analyses of Amides and Amide Dimers of Steviol, Isosteviol, and Steviolbioside
}

\author{
Lin-Wen Lee, ${ }^{1}$ Tzong-Huei Lee, ${ }^{2}$ Ching-Tung Lin, ${ }^{3}$ Tiffany Chen, ${ }^{4}$ and Pen-Yuan Lin ${ }^{5}$ \\ ${ }^{1}$ Department of Microbiology and Immunology, College of Medicine, Taipei Medical University, \\ 250 Wu-Hsing Street, 11031 Taipei, Taiwan \\ ${ }^{2}$ Graduate Institute of Pharmacognosy, College of Pharmacy, Taipei Medical University, 250 Wu-Shing Street, \\ Taipei 11031, Taiwan \\ ${ }^{3}$ Department of Chemistry, Tamkang University, 151 Yingzhuan Road, Danshui District, 25137 New Taipei City, Taiwan \\ ${ }^{4}$ Departments of Biochemistry and Chemistry, University of Washington, 4311 11th Avenue NE, Seattle, WA 98105-4068, USA \\ ${ }^{5}$ Department of Medicinal Chemistry, College of Pharmacy, Taipei Medical University, 250 Wu-Shing Street, Taipei 11031, Taiwan
}

Correspondence should be addressed to Pen-Yuan Lin, lpy0620@tmu.edu.tw

Received 6 July 2011; Revised 30 November 2011; Accepted 11 December 2011

Academic Editor: Karol Jackowski

Copyright ( 2012 Lin-Wen Lee et al. This is an open access article distributed under the Creative Commons Attribution License, which permits unrestricted use, distribution, and reproduction in any medium, provided the original work is properly cited.

The mass spectra of a series of stevioside analogues including the amide and dimer compounds of steviol, isosteviol, and steviolbioside were examined. Positive ion mass spectral fragmentation of new steviol, isosteviol, and steviolbioside amides and the amide dimers are reported and discussed. The techniques included their synthesis procedures, fast-atom bombardment (FAB), and $\mathrm{LC} / \mathrm{MS} / \mathrm{MS}$ mass spectra. Intense $[\mathrm{M}+\mathrm{H}]^{+}$and $[\mathrm{M}+\mathrm{Na}]^{+}$ion peaks were observed on the FAB and ESI spectra. LC/MS/MS also yielded ES+ and ES - ion peaks that fairly agreed with the results of the FAB and ESI studies. Mass spectral analysis of compounds 4p-q, 5a-g, 6, and 7 revealed the different cleavage pathway patterns that can help in identifying the structures of steviolbioside and its amide derivatives.

\section{Introduction}

1.1. Fragmentation Pattern of Steviolbioside Amide Derivatives. The mass spectrometry of these safe and sweet compounds such as steviol, isosteviol, and steviolbioside and their amides and amide dimer derivatives are an interesting current subject. Some reports [1] indicated that more than 50 of kaurane derivatives had been reviewed and presented in terms of specific activities which are antiparasitic, antimicrobial, antifertility, anti-inflammatory, and steroidogenesis. Bruno et al. [2] indicated the semisynthetic of ent-kauranes and the ester form displayed the antifeedant activity on insects. Compadre et al. [3] reported that the mass spectra analysis of this diterpenoid and its analogs revealed differences in stereochemistry, and Hussain et al. [4] used chemical ionization mass spectra to examine steviol and its aglycone. There were many reports to mention the toxicities [5], metabolism [6], bioactivities [7], microbial transformations [8], anti-HIV effects [9], genotoxicity [10], anti- inflammatory effects [11], and synthesis [12-14] of steviol, stevioside, isosteviol, and their derivatives dimers [15]. In this paper, we report our works on steviol derivatives, steviolbioside, and their synthetic compounds which were examined by a number of mass spectrometric techniques including electron impact (EI), fast atom bombardment (FAB), and electrospray with tandem mass spectrometry LC/MS/MS ESI.

\section{Experimental}

For the synthetic purpose, steviol, isosteviol, and steviolbioside were prepared from stevioside, which was as obtained parts from plant extracts in China and purchased from Kyowa Foods Co. (Japan) as commercial food additives, via hydrolysis and purification by chromatography. The IR and NMR spectra were identified with those of the authentic sample $[8,12]$.

In the typical synthesis of amide reactions, alkylamines (1.1 eq) or alkyldiamines (2.1 eq) were added to a solution of 
TABLE 1: Main ions observed in FAB mass spectra of compounds 5, 6, and 7.

\begin{tabular}{|c|c|c|c|c|}
\hline \multicolumn{2}{|c|}{ Compd. } & \multirow{2}{*}{$\begin{array}{c}\text { FAB ions: } m / z(\text { rel. abundance } \%) \\
1331(10), 1332(7), 775(2), 661(10)\end{array}$} & \multicolumn{2}{|c|}{$[\mathrm{M}+\mathrm{Na}]^{+}[\mathrm{M}+\mathrm{H}]^{+}$Cald./Measd } \\
\hline \multirow[t]{3}{*}{$5 a$} & $n=2$ & & & \\
\hline & & $643(6), 307(12), 154(100), 137(56)$ & & \\
\hline & & 136(90), 107(39), 95( 37), 73(51), 55(81) & 1309.6 & 1331.0 \\
\hline \multirow[t]{4}{*}{$5 b$} & $n=4$ & 1360(4), 1359(5), 690(7), 689(13), 671(6) & & \\
\hline & & $625(5), 581(6), 537(7), 493(6), 449(5)$ & & \\
\hline & & 391(6), 308(7), 307(32), 289(22), 255(10) & 1337.6 & 1360.0 \\
\hline & & 154(100), 136(95) & & \\
\hline \multirow[t]{3}{*}{$5 c$} & $n=5$ & 1373(32), 1374(24), 1375(9), 1239(3), 1049(4), & & \\
\hline & & 817(6), 703(9), 685(7), 619(8), 493(6), 363(5), & & \\
\hline & & $154(73), 55(100)$ & 1351.6 & 1373.0 \\
\hline \multirow[t]{4}{*}{$5 d$} & $n=7$ & 1401(4),1379(1), 876(2), 731(67), 713(31), & & \\
\hline & & 714(18), 391(85), 392(38), 391(85), 308(22), & & \\
\hline & & 307(72), 289(63), 279(27), 222(35), 219(21), & & \\
\hline & & $154(100), 136(98)$ & 1379.7 & 1401.0 \\
\hline \multirow[t]{3}{*}{$5 e$} & $n=8$ & 1415(8), 1416(4), 1091(3), 859(3), 745(17), & & \\
\hline & & 727(9), 329(12), 307(36), 289(26), 255(19), & & \\
\hline & & $154(100), 136(97)$ & 1393.7 & 1415.0 \\
\hline \multirow[t]{4}{*}{$5 f$} & $n=10$ & 1444(9), 1443(12), 1309(2), 773(5),619(4), & & \\
\hline & & $338(11), 155(20), 154(75), 152(12), 138(25)$ & & \\
\hline & & 137(43), 136(67), 109(27), 105(35), 91(68), & & \\
\hline & & $81(52), 77(61), 67(51), 55(100)$ & 1421.7 & 1443.0 \\
\hline \multirow[t]{4}{*}{$5 g$} & $n=12$ & 1471(4), 1472(2), 1175(1), 1148(2), 915(2), 801(14), & & \\
\hline & & 783(7), 619(4), 338(13), 307(14), 155(38) & & \\
\hline & & 154(100), 137(67), 136(92), 109(48), 105(55), & & \\
\hline & & $77(69), 67(54), 55(82)$ & 1449.8 & 1471.0 \\
\hline \multirow[t]{2}{*}{6} & $n=2$ & $661(23), 600(12), 579(9), 359(27), 341(47)$ & & \\
\hline & & $267(32), 154(98), 57(100), 55(85)$ & 660.5 & 661.5 \\
\hline 7 & $n=2$ & $661(100), 344(25), 273(52), 177(15)$ & 661.0 & 661.5 \\
\hline
\end{tabular}

title compounds (1.0 eq) in dried DMF $(6 \mathrm{~mL})$ at room temperature. The mixture was cooled to $0^{\circ} \mathrm{C}$, and 1-benzo- triazolyoxytri (pyrrolidino)phosphonium hexafluorophosphate (PyBOP) (1.1 eq or $2.2 \mathrm{eq}$ ) in dimethy formamide (DMF) was added followed by $5.0 \mathrm{eq}$ of diisopropylethylamine (DIEA). After $12 \sim 72 \mathrm{~h}$ at room temperature or $60^{\circ} \mathrm{C}$, the reaction mixture was evaporated and purified by using silica column chromatography and eluted with a gradient solvent system containing $\mathrm{CHCl}_{3}, \mathrm{MeOH}$, and $\mathrm{H}_{2} \mathrm{O}$. The structures of all derivatives were recorded on $500 \mathrm{MHz}$ NMR, IR, FABMS, and LC/MS/MS ESI [16].

High-resolution measurements were obtained by using a High-Resolution Mass Spectrometer (Finnigan/Therwo Quest MAT 95XL). The other resolution experiments were performed on Mass-Spectrometer (JEOL JMX-HX 110 and JEOL JMX-DX 300). For both low- and high-resolution FAB mass spectra were obtained using a JEOL JMX SX/SX 102 A spectrometer. Computerized peak matching was employed with measured masses being within $10 \mathrm{ppm}$ of all calculated values. All the experiments were performed at $70 \mathrm{eV}$ (electron spray ionization, ESI). LC/MS/MS spectra were record- ed using a micromass Quattro II triple-quadruple mass spectrometer by injection $5 \mu \mathrm{L}$ of each sample. Argon was used as the collision gas and the collision energy was in the range of $2 \sim 9 \mathrm{eV}$. The samples were dissolved in methanol to proper solutions with concentrations of $5 \mu \mathrm{L}$ ( $50 \mu \mathrm{g} / \mathrm{mL}$, in $5 \mu \mathrm{L} 50 \%$ $\mathrm{MeOH}$ ) for analysis.

\section{Test Compounds}

As shown in Scheme 3, sample of compounds 4, 5, 6, and 7 was prepared by previous method.

\section{Results and Discussion}

A series of substituted steviolbioside amides and amide dimers obtained from the synthesis of title compounds have been investigated by FAB-MS in our laboratory. Some steviolbioside derivative molecules exhibited molecular ion of low intensity and showed the main fragmentation corresponded to the loss of their side chains, such as the sugar adjacent to the nitrogen atom. Steviolbioside $\mathbf{3}$ has a free carboxylic acid 


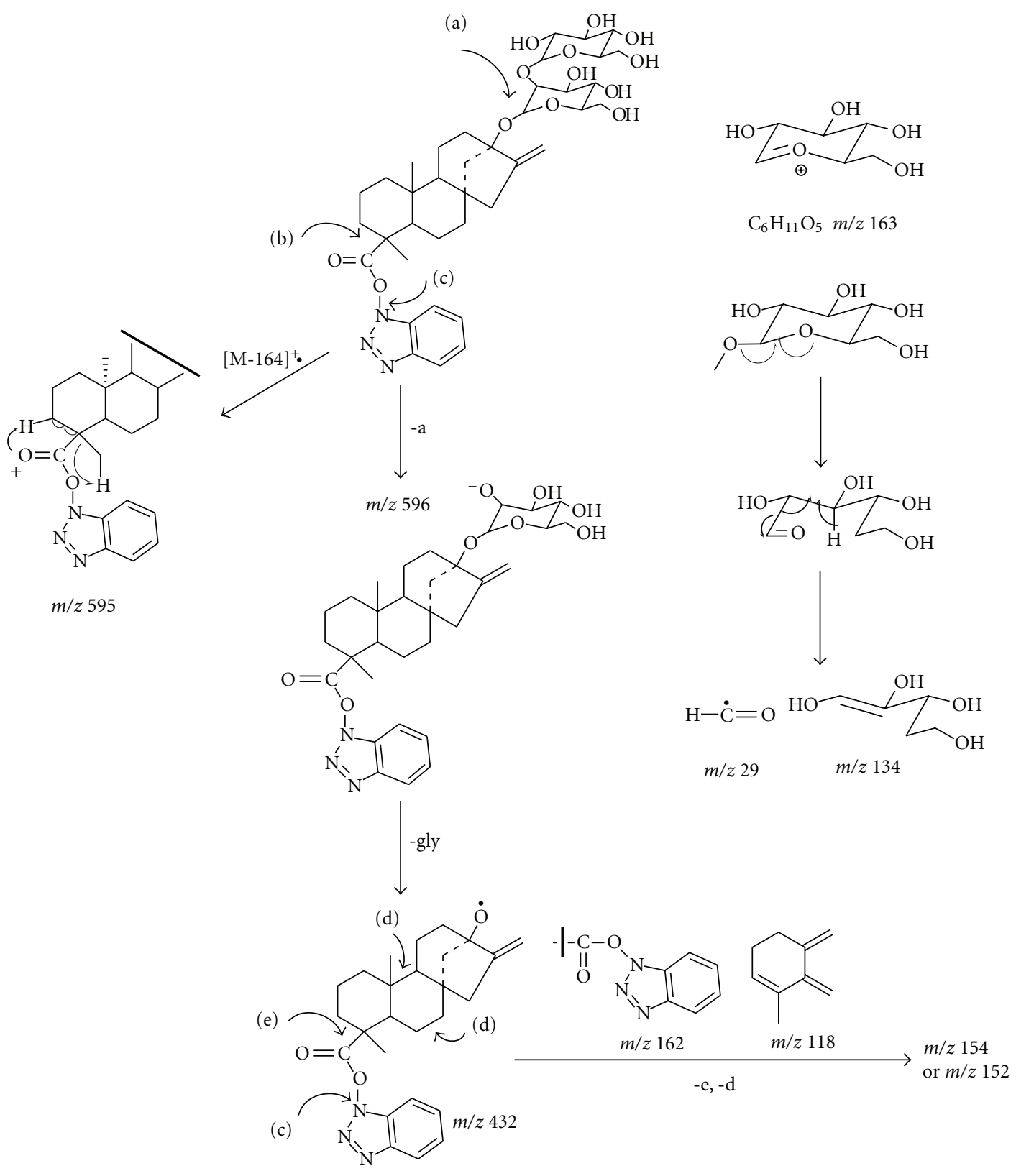

Scheme 1: Proposed fragmentation pathway leading to the generation of fragment peaks from steviolbioside-intermediate (linkage with benzotriazolyl).

at the carbon- 4 position of skeleton. In order to facilitate the recognition of these compounds, we produced its indolyl amide $\mathbf{4 p}$, steary amide $\mathbf{4 q}$, and oleyl amide $\mathbf{4 r}$ in good yields $(81 \%-86 \%)$. In the same way, the steviolbioside amide dimers $5 \mathbf{a}-\mathbf{5 g}, \mathbf{6}$, and 7 were prepared by using various alkyldiamines ( $n=2,4,5,7,8,10$, and 12) (Scheme 3). Among these diamine derivatives, aromatic diamines did not seem to react with bulkyl steviolbioside even in their ami- nation reactions. We did not obtain the aromatic amides from this work that might be explained by the weak basicity of the aniline derivatives; the $\mathrm{pKa}$ values of the anilines or rather anilinium ions were around $4.8 \sim 5.4$. In this work, the elec- tron donor effects seemed to enhance the resultant amination reactions, and we observed that these glycoside sugars did not perturb amide reactions or amide dimer couplings.

Based on the mass spectra, the proposed general fragmentation patterns were elucidated. The parent derivatives, compounds $4 \mathbf{p}-4 \mathbf{r}, 5 \mathbf{a}-5 \mathrm{~g}, \mathbf{6}$, and 7 all gave the different spectra $\mathrm{FAB}[\mathrm{M}+\mathrm{Na}]^{+},[\mathrm{M}+\mathrm{H}]^{+}, \mathrm{LC} / \mathrm{MS} / \mathrm{MS}[\mathrm{M}+\mathrm{Na}] \mathrm{ES}^{+}$, and $\mathrm{ES}^{-}$, as shown in Tables 1 and 2.

In the case of the 2-indolylethyl steviolbioside amide $4 \mathrm{p}$, the fragmentation pathways proposed for the molecule ion $[\mathrm{M}+\mathrm{Na}],\left[\mathrm{C}_{42} \mathrm{H}_{58} \mathrm{~N}_{2} \mathrm{O}_{12} \mathrm{Na}\right]^{+}$are shown in Figure 1 and Scheme 2. The main fragmentation pathway can be 
<smiles>CC/C=C\CC(=O)NC(C)Cc1c[nH]c2ccccc12</smiles><smiles>CCc1c[nH]c2ccccc12</smiles>

$\mathrm{m} / z 158$<smiles>NCCc1c[nH]c2ccccc12</smiles><smiles>CCCCc1c(CCCNC(C)=O)cc2n1-c1ccccc1-2</smiles><smiles>C=C1C=Nc2ccccc21</smiles><smiles>[GeH3][GeH3]</smiles>
$m / z 129$<smiles>F/C=C/c1c[nH]c2ccccc12</smiles>
$\mathrm{m} / z 143$ 3

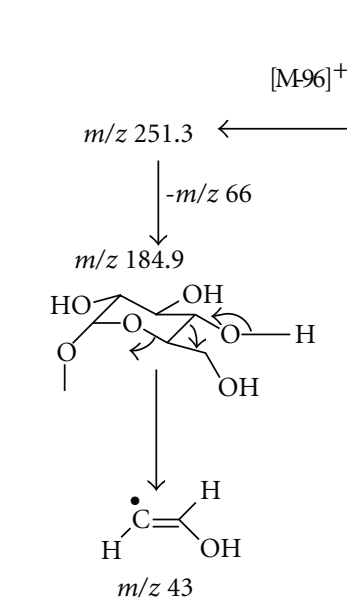
$m / z 144$<smiles></smiles>

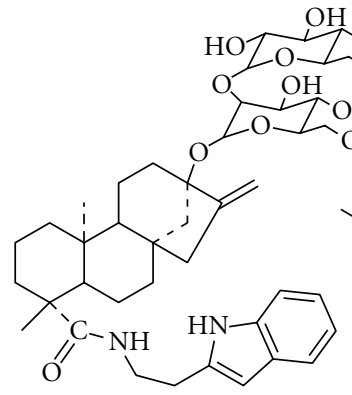

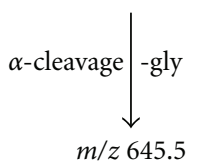<smiles>C=C1CNc2ccccc21</smiles>

M-96 $]^{+}$

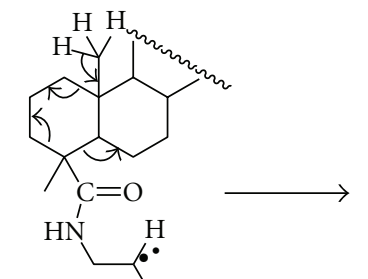

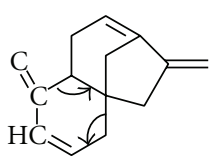<smiles>[H][Z11]([H])=CC=C</smiles><smiles>C/C=C1\C=Nc2ccccc21</smiles>

[M-143] ${ }^{+}$<smiles>C=C(C)C(=O)NCCCC</smiles>

$\mathrm{C}_{6} \mathrm{H}_{11} \mathrm{NO}^{+}, m / z 114$<smiles>C=C=CC=C</smiles>

Scheme 2: Proposed fragmentation pathway leading to the generation of Fragment Peaks from steviolbioside amide 4p.

described by two major events. (1) $\alpha$-Cleavage at the C$\mathrm{C}$ bond resulted in the loss of ethylindolyl, and $\beta$-cleavage resulted in the loss of methylindolyl moieties producing the formation of molecules and the simultaneous rearrangement of the resulting fragment-formed ion generation at $\mathrm{m} / z 664.5$ and $m / z$ 347.1. (2) The main peaks at $m / z 459.4,621.5$ and $\mathrm{m} / \mathrm{z} 603.4$ were, respectively, found to eliminate 2 glucose, 1 glucose, and 1 o-glucose molecules or indolyl from the parent peaks (Figure 1). In the FAB mass spectra of compound $\mathbf{4 q}$, we observed that the main peak was formed by the molecule, $\left[\mathrm{C}_{50} \mathrm{H}_{87} \mathrm{NO}_{12}\right]^{+}$at $\mathrm{m} / z 893$ and fragment species at $m / z 731$ and 556. This could have been due to the lost of 1 and 2 glucose molecules. In its LC/MS/MS spectra, we observed an intense peak at $m / z$ 916.6, which was found to be characteristic of the $\mathrm{N}$-stearyl steviolbioside amide $\mathbf{4 q}$, with $[\mathrm{M}+\mathrm{Na}]^{ \pm}$and the elimination of 1 glucose specie at $\mathrm{m} / \mathrm{z}$ 754.3. Further loss of the second glucose was occurred mainly through $\mathrm{C}-\mathrm{C}$ bond $\beta$-cleavage with the loss of the branching part of $\mathrm{C}_{16} \mathrm{H}_{33}$ in the stearyl amide at $m / z$ 365.1. Followed by elimination of water at position $\mathrm{C}-13$, the fragment ion was formed at $m / z 347.1$ (Table 2 ). In compound $4 \mathbf{r}$, we observed that the base peak was the $4 \mathbf{r}$ molecule $\left[\mathrm{C}_{50} \mathrm{H}_{85} \mathrm{NO}_{12}\right]^{ \pm}$at $\mathrm{m} / z$ 891 in the FAB mass spectra. With the further loss of 1 , and 2 glucoses molecules, two product ions at $\mathrm{m} / \mathrm{z} 729$ and $\mathrm{m} / \mathrm{z}$ 567 were produced, respectively. In its LC/MS/MS spectra we observed the molecule peak with $\mathrm{Na}$ at $\mathrm{m} / z 914.5$ and some relative intensities of fragment ion peaks at $m / z 858.4$ (loss of a butyl species of oleyl), at $m / z 752.5$ (loss of 1 glucose from the $m / z 774.6$ fragment ion), and at $m / z 612.6$ (loss of 2 glucoses molecules and $\mathrm{Na}$ from the molecule peak). We also 

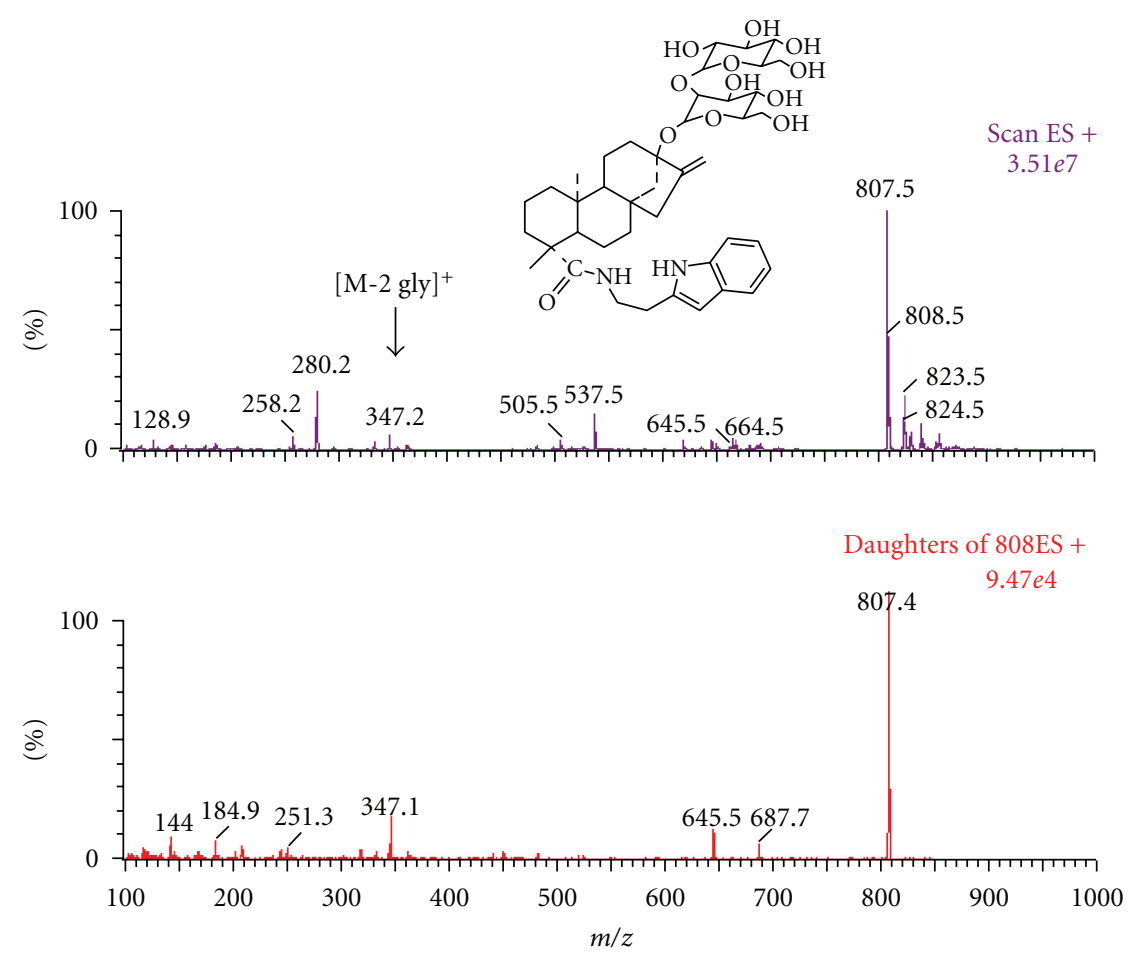

(a)
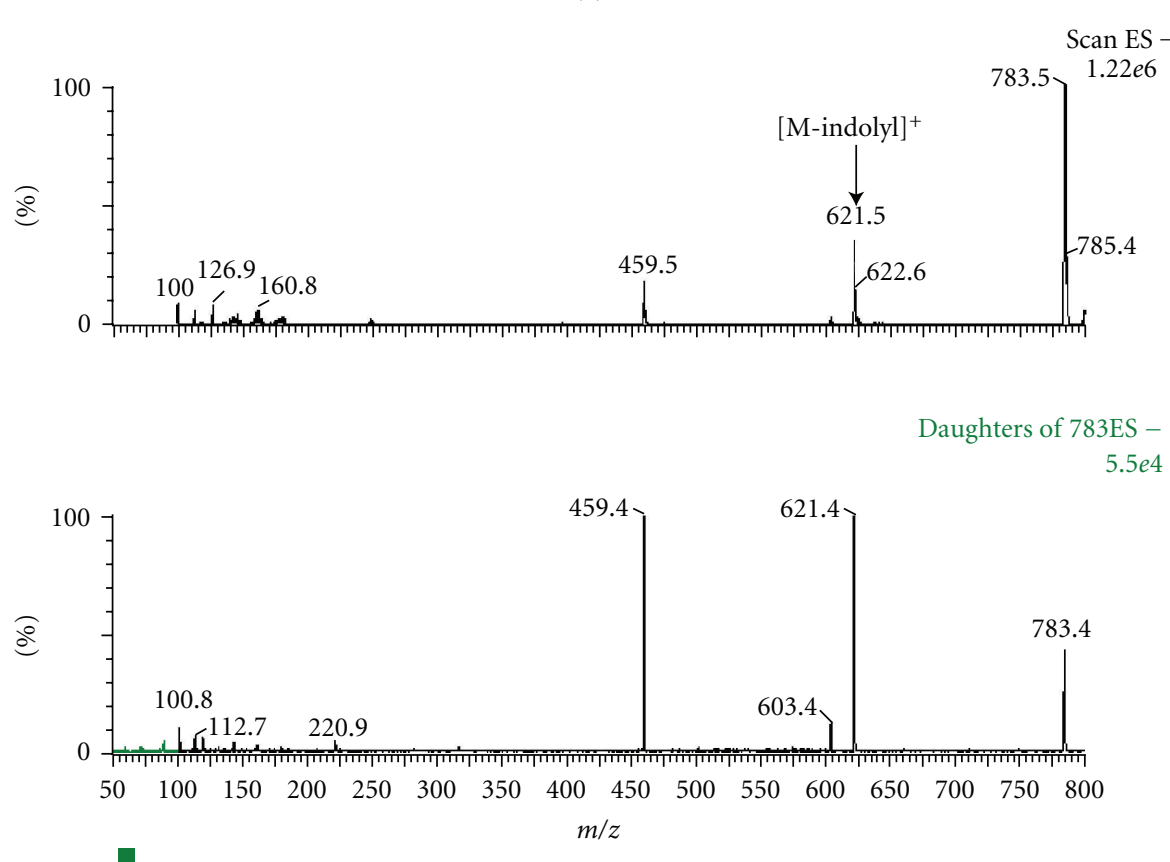

(b)

Figure 1: LC/MS/MS spectra of Steviolbioside $4 p[\mathrm{p}+\mathrm{Ma}]^{+}$and $[\mathrm{M}-\mathrm{H}]^{-}$.

observed a small fragment species at $\mathrm{m} / \mathrm{z} 365.2$; this could have been due to the loss of 2 glucose molecules and the $\mathrm{C}-\mathrm{C}$ bond $\beta$-cleavaged to amine nitrogen with loss of the $\mathrm{C}_{16} \mathrm{H}_{31}$ moiety from the olelyl group followed by loss of water (at $\mathrm{m} / \mathrm{z}$ 347.2). An interesting fragment was observed at $\mathrm{m} / \mathrm{z} 207.0$ that was assumed to occur through $\gamma$-cleavage from the side chain of olelyl. In its ES ${ }^{-}$fragmentation pattern we observed some intense fragment species at $\mathrm{m} / \mathrm{z} 864.4$ and $\mathrm{m} / \mathrm{z}$ 836.4; and it was assumed that they were the result of the loss of ethyl and butyl molecules of side chains of oleyl. 

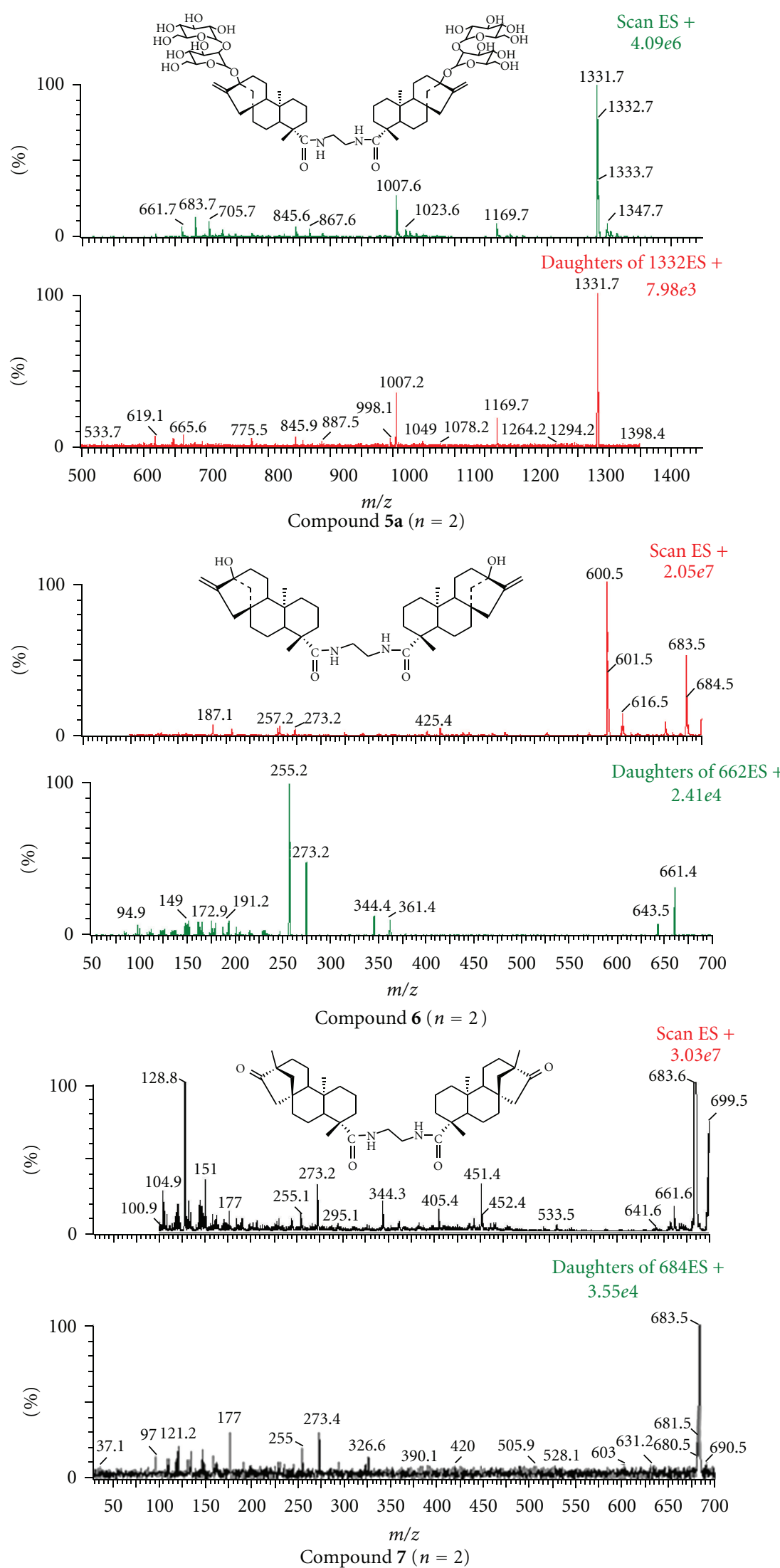

Figure 2: LC/MS/MS spectra of Steviolbioside dimer 5a $[\mathrm{M}+\mathrm{Na}]$, steviol amide dimer $\mathbf{6}[\mathrm{M}+\mathrm{Na}]$, and Isosteviol amide dimer 7 [M+Na]. 
TABLE 2: LC/MS/MS/ESI determination of main fragmentation pathway for compounds 1-7.

\begin{tabular}{|c|c|c|c|}
\hline \multirow[t]{2}{*}{ Compds } & \multicolumn{2}{|c|}{ Precursor ion mass $[\mathrm{M}+\mathrm{Na}]^{+}$} & \multirow[t]{2}{*}{ Product ion masses (intensity\%) } \\
\hline & ESI+ & ESI- & \\
\hline \multirow[t]{2}{*}{1} & 357.3 & & $357.2(100), 342.6(3)$ \\
\hline & & & 299.5(2),224.6(2), 197.1(4) \\
\hline \multirow[t]{2}{*}{2} & & $317.3,318.3$ & 317.3(100), 273.2(63), 271.1(43), \\
\hline & & & $119.9(6), 109.0(8), 93.9(5)$ \\
\hline \multirow[t]{7}{*}{3} & $665.4,666.4$ & & 665.3(100),547.3(3), 507.3(5), \\
\hline & & & 363.3(2), 347.2(3), 151.0(21) \\
\hline & & & $104.9(12)$ \\
\hline & & $641.4,642.4,643.4$ & 641.3(30),479.3(100), 461.3(10), \\
\hline & & & 371.4(2), 338.9(12), 317.2(78), \\
\hline & & & 118.9(18), 112.8(35), 100.8(90), \\
\hline & & & $58.9(60)$ \\
\hline \multirow[t]{5}{*}{$4 p$} & $807.5,808.5$ & & 807.4(100), 687.7(4), 645.5(6), \\
\hline & & & $347.1(17), 251.3(3), 184.9(5)$ \\
\hline & & $783.5,785.4$ & 783.4(46), 621.4(98), 603.4(7) \\
\hline & & & 459.4(100), 220.9(2), 112.7(3), \\
\hline & & & $100.8(5)$ \\
\hline \multirow[t]{4}{*}{$4 q$} & 916.6,917.6, & & 916.4(100), 796.7(3), 754.3(4) \\
\hline & & & $347.1(35), 185.0(5)$ \\
\hline & & 892.5 & 892.6(100), 730.5(3), 568.5(5), \\
\hline & & & $161.0(50), 100.8(35)$ \\
\hline \multirow[t]{4}{*}{$4 r$} & 914.5 & & 914.5(100), 794.5(6), 752.4(18), \\
\hline & & & $347.1(28)$ \\
\hline & & $890.5,891.5$ & 566.5(20), 161.0(35), 112.8(43), \\
\hline & & & $100.8(100), 70.9(33)$ \\
\hline \multirow[t]{2}{*}{$5 a$} & $1331.7,1332.7,1333.7$ & & 1331.7(100), 1169.7(20), 1007.2(35) \\
\hline & & & $998.1(5), 887.5(2), 619.1(4)$ \\
\hline \multirow[t]{3}{*}{$5 b$} & $1360.0,1360.9,1361.9$ & & 1359.7(100), 1197.5(3), 1035.6(4) \\
\hline & & $1335.8,1336.8,1337.8$ & 1335.6(100), 1173.6(40) \\
\hline & & & 1011.5(21), 849.6(7), 687.5(100) \\
\hline \multirow[t]{4}{*}{$5 c$} & $1374.1,1375.1,1376.1$ & & 1373.6(100), 1211.5(5), 1049.6(7) \\
\hline & 1349.6 & & 1349.6(38), 1187.5(25), \\
\hline & & & 1025.7(20), \\
\hline & & & $863.7(6), 701,6(100), 412.1(23)$ \\
\hline \multirow[t]{4}{*}{$5 d$} & $1402.2,1403.11404 .1$ & & 1401.7(100), 1239.7(15), \\
\hline & & & $1077.8(30), 915.6(22), 609.5(18)$ \\
\hline & & $1377.9,1378.9,1379.9$ & 1377.8(3), 1215.7(2),729.7(100), \\
\hline & & & $370.6(15), 112.9(18), 100.9(40)$ \\
\hline \multirow[t]{2}{*}{6} & $683.5,684.5$ & & $661.4(31), 643.5(10), 344.4(12)$ \\
\hline & & & $273.2(48), 255.2(100)$ \\
\hline 7 & 683.6 & & 683.5(100), 273.4(30), 255.0(20), \\
\hline & & & $177.0(30)$ \\
\hline
\end{tabular}

4.1. Fragmentation Pattern of Amide Dimers of Steviolbioside. The LC/MS/MS spectra produced from the steviolbioside derivatives $\mathbf{5 a} \sim \mathbf{5} \mathrm{g}$ revealed the most favorable fragmentation processes with losing the initial 1, 2, 3, and 4 glucose molecules from the $[\mathrm{M}+\mathrm{Na}]^{+}$ion, followed by elimination of $\mathrm{Na}$ and water (at position $\mathrm{C}-13$ ) and side chains to from the ion peak, such as for $\mathbf{5 a}(n=2)$ at $m / z 1169.7,1007.6$, 845.6, 683.7, and 665.6 (loss of water) (Figure 2, Table 2); 5b $(n=4)$ at $m / z 1173.7,1011.7,849.7$, and $687.7 ; 5 c$ $(n=5)$ at $m / z 1212.0,1049.9,887.8$, and 725.8, and $5 \mathbf{d}$ $(n=7)$ at $m / z 1215.8,1053.8,891.8$, and 729.8. In the $\mathrm{FAB}^{+}$mass spectra $[\mathrm{M}+\mathrm{Na}]^{ \pm}$of $5 \mathbf{e}, 5 \mathbf{f}$, and $5 \mathrm{~g}$, was at $\mathrm{m} / \mathrm{z}$ 1415,1443 , and 1471. Loss of 4 glucose molecules and $\mathrm{Na}$ occurred at $m / z 745,773$, and 801. A similar fragmentation pathway of $5 \mathbf{a}-\mathbf{g}$ has been proposed for the steviolbioside amide dimer in $\mathrm{FAB}^{+}$spectra, such as $5 \mathbf{a}$ at $m / z 1164,983$, 822 , and $660 ; 5$ b at $m / z 1196,1034,870$, and 710 , listed in Table 1. In these fragment peaks, we found that the elemental composition of $\mathrm{C}_{9} \mathrm{H}_{16} \mathrm{NO}$ was the base peak at $m / z 154$, and it can be assumed that the fragmentation of the $\mathrm{C}-\mathrm{C}$ bond 


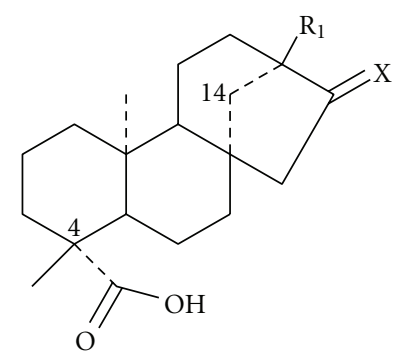

$\mathrm{R}_{1}=\mathrm{OH}, \mathrm{X}=\mathrm{CH}_{2}$, steviol 1

$\mathrm{R}_{1}=\mathrm{CH}_{3}, \mathrm{X}=\mathrm{O}, \mathrm{C}-14$ (up), isosteviol 2

$\mathrm{R}_{1}=$ O-glu-glu, $\mathrm{X}=\mathrm{CH}_{2}$, Steviolbioside 3

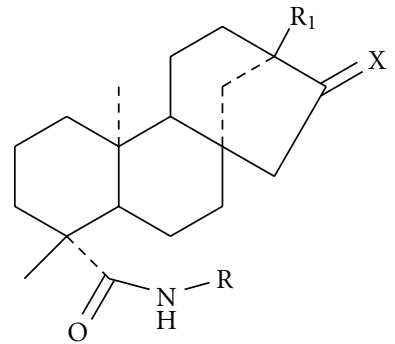

Steviolbioside amides $\left(\mathrm{R}_{1}=\mathrm{O}\right.$-glu-glu, $\left.\mathrm{X}=\mathrm{CH}_{2}\right) 4$

$$
\begin{aligned}
& \mathbf{4 p}(\mathrm{R}=\text { indolyl }) \\
& \mathbf{4 q}(\mathrm{R}=\text { stearyl }) \\
& \mathbf{4 r}(\mathrm{R}=\text { oleyl })
\end{aligned}
$$

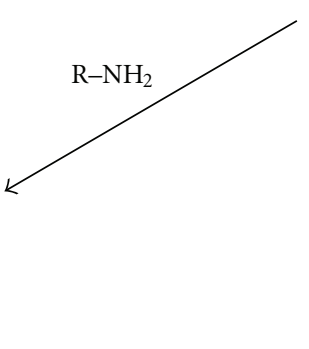

Steviolbioside amides dimers 5 5a-5g $(n=2,4,5,7,8,10,12)$

Steviol amide dimer $6(n=2)$

Isosteviol amide dimer $7(n=2)$

Scheme 3: Synthesis of amide analogues of steviol, steviolbioside, and isosteviol.

via $\alpha$-cleavage of the side chains occurred. In the LC/MS/MS spectra of compound $\mathbf{6}$, we observed an intense peak at $\mathrm{m} / \mathrm{z} 683.5$ that was the characteristic of steviol amide dimer $(n=2)$ molecule $[\mathrm{M}+\mathrm{Na}]^{ \pm}$. Its base peak at $m / z 600.5$ was probably formed by the loss of two products $\left[\mathrm{CH}_{2} \mathrm{CO}\right]^{ \pm}$and $\left[\mathrm{CH}_{2} \mathrm{CCH}_{2}\right]^{ \pm}$, which were produced by the opening of the $\mathrm{C} / \mathrm{D}$ ring of steviolbioside. We also observed in the daughter spectrum that the molecular peak was at 661.4 and loss of $1 \mathrm{H}_{2} \mathrm{O}$ molecule was at $m / z 643.5$. In the parent peak at $\mathrm{m} / \mathrm{z}$ 273.2 and the base peak there was the loss of a water molecule at $m / z$ 255.2. In compound 7 , we checked the $\mathrm{FAB}^{+}$mass spectrum at $m / z 661$ as a base peak $[\mathrm{M}+\mathrm{H}]^{+}$and the parent peak at $m / z 273$ and its LC/MS/MS spectra of the isosteviol amide dimer $(n=2)$. It seemed to be the same fragmentation pattern as compound $6 .[\mathrm{M}+\mathrm{Na}]^{ \pm}$peak was at $\mathrm{m} / z 683.6$ and there was a loss of $\mathrm{Na}$ at $\mathrm{m} / \mathrm{z}$ 661.6, followed by losing of $\left[\mathrm{CH}_{2} \mathrm{CO}\right]^{ \pm}$at the $\mathrm{D}$ ring to form the fragment species at $m / z 641.6$ and to produce an intense second-generation ion at $m / z$ 451.4. The C-N bond was then cleaved to form the peaks at $\mathrm{m} / \mathrm{z} 344.3$ and 273.2. It probably was formed by the cleavage of the $\mathrm{C}-\mathrm{C}$ bond resulting in the formation of species "d" (Scheme 1) at $\mathrm{m} / z 121.2$ and 151.0 followed by the loss of Na to form the base peak at $\mathrm{m} / \mathrm{z}$ 128.8. (Scheme 1).

In conclusion, due to the observed fragmentation pattern pathways, cleavage formed and their generated peaks further encourage us to check the synthetic products in biological modification that will be useful in future studies on natural products.

\section{Acknowledgments}

The authors wish to acknowledge Mrs. Fan-Ing Lin Hsu for financial support and Professors. D.W-M Liang and S-T Lin for helpful discussions during the course of this work. They are also thankful to professors. Emil T. Lin of the University of California at San Francisco (UCSF) for recording the LC/MS/MS ESI mass spectra.

\section{References}

[1] V. Křen and L. Martínkové, "Glycosides in medicine: 'The role of glycosidic residue in biological activity," Current Medicinal Chemistry, vol. 8, no. 11, pp. 1303-1328, 2001.

[2] M. Bruno, S. Rosselli, I. Pibiri, N. Kilgore, and K. H. Lee, "Anti-HIV agents derived from the ent-kaurane diterpenoid linearol," Journal of Natural Products, vol. 65, no. 11, pp. 15941597, 2002.

[3] C. M. Compadre, R. A. Hussain, N. P.D. Nanayakkara, J. M. Pezzuto, and A. D. Kinghorn, "Mass spectral analysis of some derivatives and in vitro metabolites of steviol, the aglycone of the natural sweeteners, stevioside, rebaudioside $\mathrm{A}$, and 
rubusoside," Biomedical and Environmental Mass Spectrometry, vol. 15, no. 4, pp. 211-222, 1988.

[4] R. A. Hussain, A. B. Schiling, and A. D. Kinghorn, "Chemical ionization mass spectral characteristics of analogs of steviol, the aglycone of the plant-derived sweetening agent, stevioside," Biomedical And Environmental Mass Spectrometry, vol. 19, no. 2, pp. 63-68, 1990.

[5] J. M. C. Geuns, V. Bruggeman, and J. G. Buyse, "Effect of stevioside and steviol on the developing broiler embryos," Journal of Agricultural and Food Chemistry, vol. 51, no. 17, pp. 51625167, 2003.

[6] E. Koyama, K. Kitazawa, Y. Ohori et al., "In vitro metabolism of the glycosidic sweeteners, stevia mixture and enzymatically modified stevia in human intestinal microflora," Food and Chemical Toxicology, vol. 41, no. 3, pp. 359-374, 2003.

[7] G. L. Anderson, D. L. Bussolotti, and J. K. Coward, "Synthesis and evaluation of some stable multisubstrate adducts as inhibitors of catechol O-methyltransferase," Journal of Medicinal Chemistry, vol. 24, no. 11, pp. 1271-1277, 1981.

[8] F.-L. Hsu, C.-C. Hou, L.-M. Yang et al., "Microbial transformations of isosteviol," Journal of Natural Products, vol. 65, no. 3, pp. 273-277, 2002.

[9] M. Bruno, S. Rosselli, I. Pibiri, N. Kilgore, and K. H. Lee, "Anti-HIV agents derived from the ent-kaurane diterpenoid linearol," Journal of Natural Products, vol. 65, no. 11, pp. 15941597, 2002.

[10] M. Matsui, K. Matsui, Y. Kawasaki et al., "Evaluation of the genotoxicity of stevioside and steviol using six in vitro and one in vivo mutagenicity assays," Mutagenesis, vol. 11, no. 6, pp. 573-579, 1996.

[11] K. Yasukawa, S. Kitanaka, and S. Seo, "Inhibitory effect of stevioside on tumor promotion by 12-O- tetradecanoylphorbol13 -acetate in two-stage carcinogenesis in mouse skin," Biological and Pharmaceutical Bulletin, vol. 25, no. 11, pp. 1488-1490, 2002.

[12] T. Ogawa, M. Nozaki, and M. Matsui, "Total synthesis of stevioside," Tetrahedron, vol. 36, no. 18, pp. 2641-2648, 1980.

[13] G. E. DuBois, P. S. Dietrich, J. F. Lee, G. V. McGarraugh, and R. A. Stephenson, "Diterpenoid sweeteners. Synthesis and sensory evaluation of stevioside analogues nondegradable to steviol," Journal of Medicinal Chemistry, vol. 24, no. 11, pp. 1269-1271, 1981.

[14] G. E. DuBois and R. A. Stephenson, "Diterpenoid sweeteners. Synthesis and sensory evaluation of stevioside analogues with improved organoleptic properties," Journal of Medicinal Chemistry, vol. 28, no. 1, pp. 93-98, 1985.

[15] V. A. Alfonsov, G. A. Bakaleynik, A. T. Gubaidullin et al., "The first example of a tweezer-like structure in diterpene derivatives of the kaurane series," Mendeleev Communications, vol. 10, no. 5, pp. 167-206, 2000.

[16] L.-H. Lin, L.-W. Lee, S.-Y. Sheu, and P.-Y. Lin, "Study on the stevioside analogues of steviolbioside, steviol, and isosteviol 19-alkyl amide dimers: synthesis and cytotoxic and antibacterial activity," Chemical and Pharmaceutical Bulletin, vol. 52, no. 9, pp. 1117-1122, 2004. 


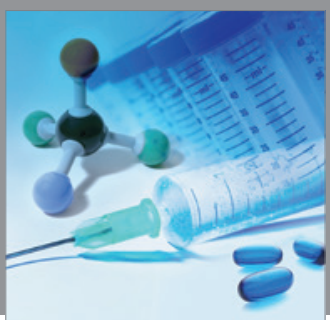

International Journal of

Medicinal Chemistry

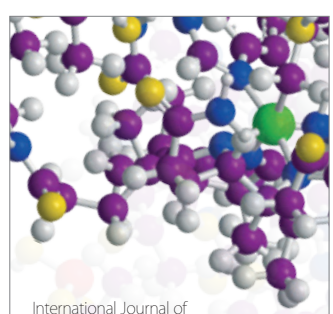

Carbohydrate Chemistry

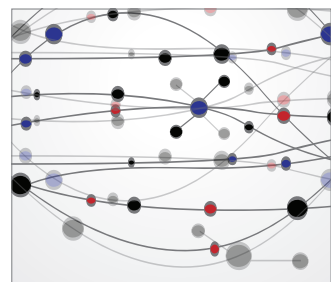

The Scientific World Journal
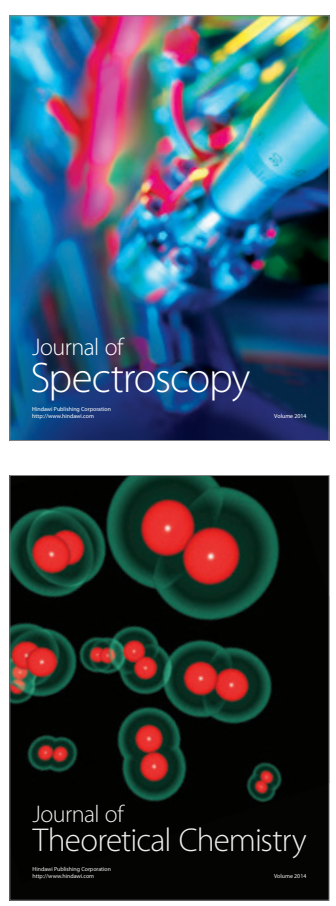
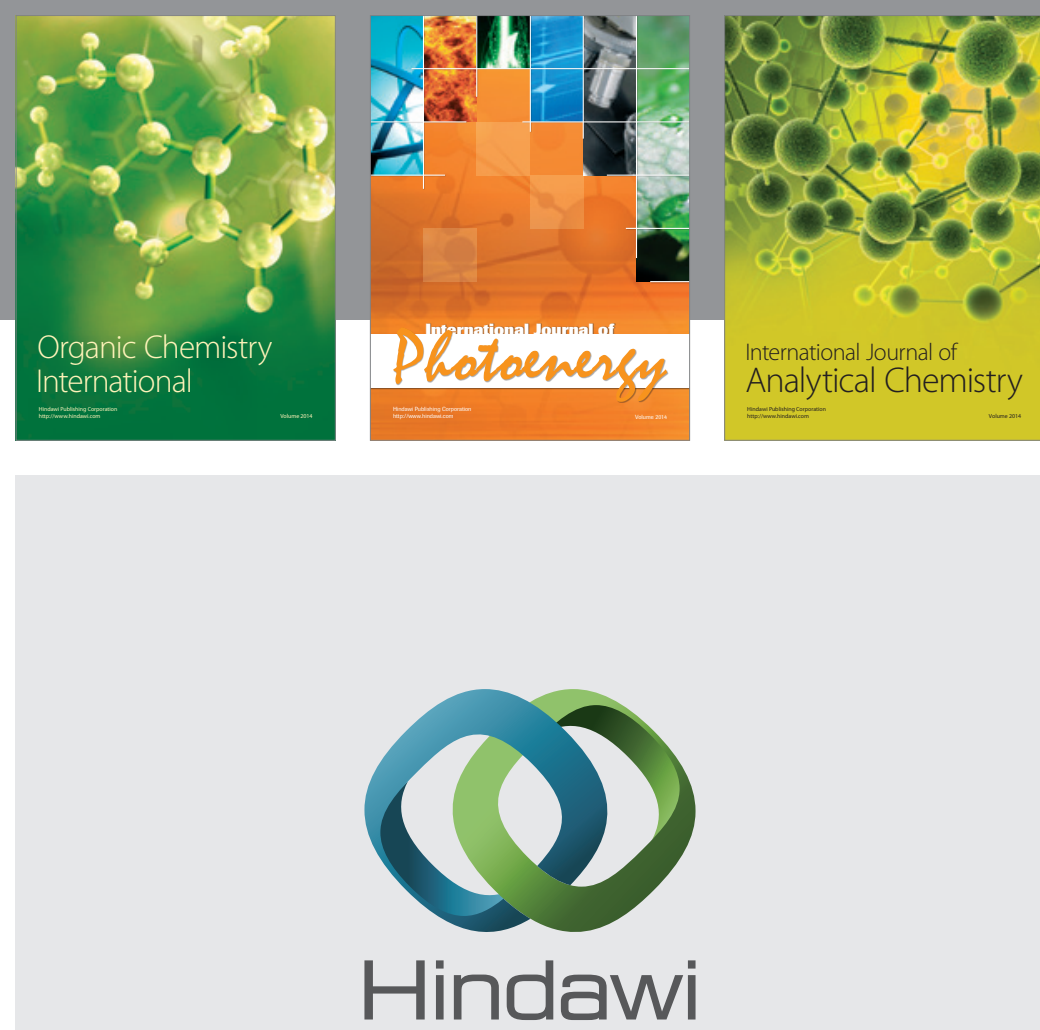

Submit your manuscripts at

http://www.hindawi.com
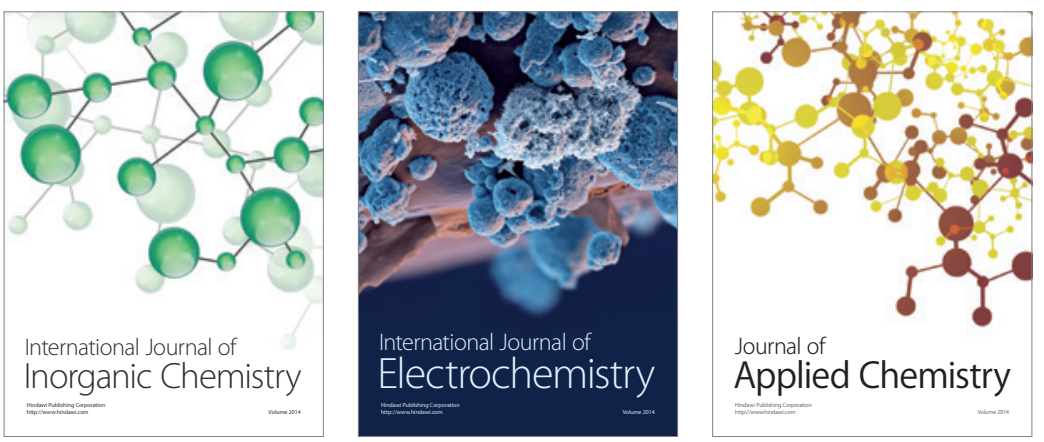

Journal of

Applied Chemistry
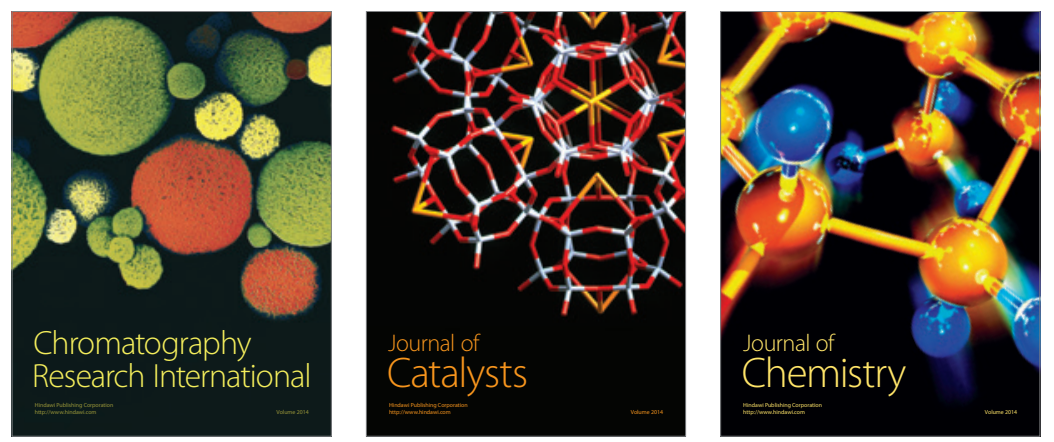
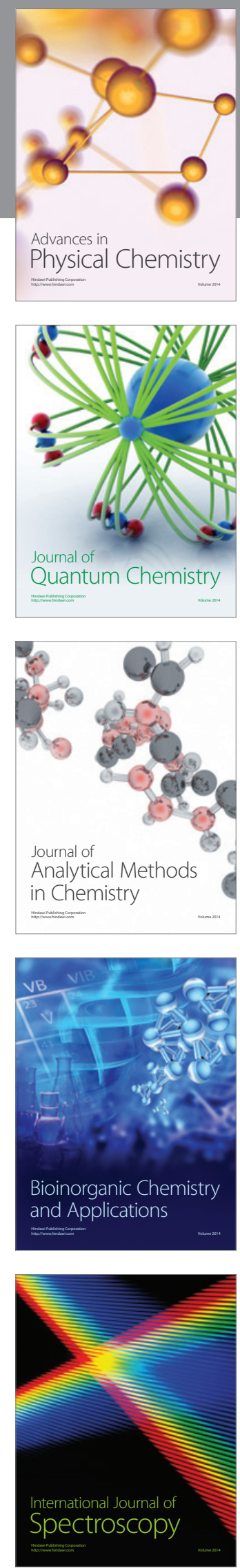